\title{
DOS LIVROS AOS TIPOS: UM INVENTÁRIO GRÁFICO DA TIPOGRAFIA DO ZÉ
}

\author{
Rafael Neder e Gisela Belluzzo de Campos
}

Design gráfico, tipografia, impressão, Flavio Vignoli, Tipografia do Zé.

books for young people, public policies to promote reading, Design in Reading.
This work has as theme the letterpress printing revival on modern times in Brazilian Graphic Design and as object the production by the Designer Flavio Vignoli and "Tipografia do Zé" (Zé's Letterpress Workshop). The research focused in to identify and analyze the designer's production characteristics, as well discuss the motives tied to his involvement with the letterpress process.

\section{INTRODUÇÃO}

Este texto é uma versão revista e ampliada de um excerto da dissertação "A prática contemporânea da impressão tipográfica no design gráfico brasileiro" desenvolvida no Programa de PósGraduação em Design da Universidade Anhembi-Morumbi no âmbito da linha de pesquisa "Design, Tecnologia e Linguagem". A pesquisa como um todo analisa a produção de designers brasileiros que se utilizam da impressão tipográfica de modo a explorar as possibilidades expressivas daquela tecnologia. Dentro desse escopo destaca-se a Tipografia do Zé, uma editora de livros artesanais formada pelo designer e professor Flavio Vignoli. O presente texto traça um breve histórico do percurso da Vignoli por considerá-lo parte importante e desconhecida da história recente do design gráfico mineiro e tece alguns comentários sobre a linguagem gráfica resultante de sua atividade. 
O relato exposto neste artigo foi construído sobretudo por meio de entrevistas realizadas pelos autores, sendo que a natureza qualitativa e o caráter exploratório da investigação fez com que se optasse pela utilização da metodologia da História Oral para a coleta e análise dos dados. A História Oral pode ser entendida como "um procedimento metodológico" capaz de "registrar, através de narrativas induzidas e estimuladas, testemunhos, versões e interpretações sobre a História em suas múltiplas dimensões" (Delgado, 2010, p. 15). Dessa maneira foi possível registrar as diferentes visões individuais formalizando-as em documentos que por sua vez permitem identificar temas relevantes a partir do entrecruzamento de informações. As entrevistas realizadas foram do tipo temática por serem mais adequadas para o registro de experiências e processos específicos vivenciados pelos depoentes. Os depoimentos foram registrados em vídeo acompanhado de um gravador de som. Posteriormente à gravação, passou-se ao processamento dos depoimentos. Como complemento, foram coletados dados em outras fontes primárias (documentos) e secundárias (livros e revistas). Assim, ao combinar esses diferentes procedimentos foi possível a elaboração desse relato.

A validade deste estudo se deve, em especial, à escasses de estudos que investigam a crescente valorização da incorporação de técnicas manuais e mecânicas ao projeto tipográfico, fenômeno perceptivel em diferetentes partes do mundo. Jury (2006) observa que o retraimento comercial da impressão tipográfica tem permitido nos últimos anos que designers e artistas gráficos interessados nas particularidades expressivas dessa tecnologia adquiram esses antigos equipamentos dando-lhes um novo fazer produtivo. Para Rocha (2011) o fato de muitos designers estarem voltando seu olhar e atenção para essas técnicas do passado, atesta a busca por uma materialidade que dificilmente pode ser emulada pela tecnologia digital. Drucker (1996) observa que pensar a materialidade do impresso gráfico evoca duas questões indissociáveis: a primeira é compreender a matéria em seu sentido literal, isto é, entender como a materialidade de um artefato é expressa pelos meios com os quais é feita, tornando-a assim tangível pelos nossos sentidos. A segunda é entendê-la como resultado de um processo cultural, como um registro das intenções, escolhas e valores de quem projetou o artefato.

\section{A TIPOGRAFIA DO ZÉ}

\subsection{1 Do teatro para o design}

Antes de se envolver com o design gráfico, Flávio Vignoli cursou direito na Universidade Federal de Minas Gerais (UFMG), área 
que logo abandonou para se dedicar ao teatro profissional. Em seu depoimento, Flávio observa que o teatro foi uma grande escola e que, no ambiente cênico, desenvolveu as funções de ator, diretor artístico, cenógrafo e iluminador. Em paralelo à sua formação no palco e nas coxias, cursou, entre os anos de 1992 e 2001, Programação Visual na Universidade do Estado de Minas Gerais (UEMG). De seus anos na faculdade, recorda-se do descompasso entre a vivência acadêmica e a profissional, o que o levou a certa desmotivação que fez com que atrasasse o curso algumas vezes.

Com o tempo, Flávio direcionou sua carreira para o design gráfico, em especial para o design de exposições e o design editorial. Entre 2003 e 2004, enquanto trabalhava na Fundação Clóvis Salgado (FCS) como chefe do departamento de artes plásticas - sendo o responsável pelo projeto e montagem de exposições -, cursou a Especialização em Artes na Escola Guignard (UEMG) e, nesse mesmo período, começou a lecionar na Universidade FUMEC - primeiramente em disciplinas no curso de Design de Interiores e, na sequência, no curso de Design Gráfico.

Segundo Flávio, o interesse pela impressão tipográfica surgiu nesse período de transição entre o teatro e o design. Leitor ávido, iniciou uma pequena - porém respeitosa - coleção de livros nos quais a qualidade do texto literário se somava à qualidade dos projetos gráficos. Dentre os diferentes itens de seu acervo, alguns se destacavam pelos aspectos táteis e materiais, livros tipográficos que refletiam uma qualidade que ele começou a perseguir em seus trabalhos profissionais. Dentre as obras de seu acervo destacam-se alguns títulos das editoras brasileiras Cattleya Alba, Dinamene, Noa Noa, O Livro Inconsútil, O Gráfico Amador, Philobiblion e Sociedade dos Cem Bibliófilos do Brasil. Outro passo importante em direção à impressão tipográfica aconteceu em 2005, já em seu próprio estúdio, quando participou conjuntamente com o professor Paulo da Terra Caldeira da curadoria da exposição de livros raros da Coleção Rita Adelaide, pertencentes ao acervo da Biblioteca Pública Estadual Luiz de Bessa. Dentre os mais de 1200 títulos da coleção, alguns livros dos séculos XVI e XVII chamaram sua atenção. Naquele momento, Flávio se preparava para seu casamento e, influenciado por esses livros, decidiu produzir seu convite utilizando essa técnica; dentre os poucos fornecedores na cidade, o escolhido foi a Tipografia Matias.

\subsection{A Tipografia Matias}

Fundada em 1958 pelo sr. Leôncio Mathias de Almeida (1915-2012) a Tipografia Matias atualmente é dirigida por Ademir Mathias de Almeida, filho mais velho de Leôncio. Embora os padrões da indústria gráfica tenham se transformado por completo nas últimas décadas do século XX, foi somente no início dos anos 2000, que a tecnologia da impressão digital fez com que a demanda por serviços de impressão 
tipográfica fosse significativamente reduzida, e com isso a empresa passou por momentos de extrema dificuldade. Contudo, ainda que no sentido contrário do setor gráfico, a empresa se manteve fiel à técnica. Essa resiliência se deve sobretudo, no caso específico da Tipografia Matias, ao valor afetivo que Ademir dá à seus tipos e máquinas, componentes de sua identidade individual e, talvez, símbolos de um passado mais simples e controlável.

Em 2005, Ademir participou de Brasil dos Ofícios Geraes, de Sávio Grossi e Marlette Menezes. No livro, os autores apresentam algumas profissões que, apesar das transformações tecnológicas, perduravam de alguma maneira: entre alfaiates, fotógrafos lambe-lambe, funileiros e outros profissionais, estava o tipógrafo. O livro foi composto e impresso por Ademir, que conjuntamente com Leôncio, foi também entrevistado para o CD-ROM que acompanhava o projeto. Foi nesse contexto e por meio dessa publicação que, no final de 2006, Flávio Vignoli conheceu Ademir Matias. Vignoli estava interessado, naquele momento, em produzir com o tipógrafo seu convite de casamento, porém tinha como condição o desejo de participar de todo o processo de produção. Assim, ao longo de algumas semanas os dois trataram de produzir o convite, numa convivência da qual surgiu uma amizade.

No segundo semestre de 2007, Flavio Vignoli apresentou o também professor e designer Rafael Neder à Ademir Matias. Rafael, naquele momento, participava de cursos da Oficina Tipográfica São Paulo, porém seu envolvimento com a impressão tipográfica acontecera alguns meses antes, em 2006, quando participou de uma oficina ministrada pelo tipógrafo jequitinhonhense Sebastião Bento. Entre 2007 e 2008, Flávio e Rafael começaram a desenvolver alguns projetos em parceria com Ademir, quando propuseram a realização de uma oficina para estudantes e profissionais de design. Com o curso, pretendiam apresentar o tipógrafo a potenciais clientes e demonstrar a tipografia como uma técnica viável para o desenvolvimento de projetos especiais; assim, em junho de 2008 aconteceu o primeiro curso.

Desde sua formulação foram realizadas cerca de 40 edições, das quais participaram aproximadamente cento e vinte alunos, muitos deles originários de diferentes estados brasileiros. Além do treinamento permitir um contato com a técnica, observa-se que o curso tornou-se um excelente canal de divulgação dos serviços da Tipografia Matias e, com a captação de novos projetos, foi possível a sobrevivência da empresa até os dias de hoje. Observa-se também que, para atender às necessidades do curso, com o tempo Flávio e Rafael adquiriram e reformaram novos equipamentos e gavetas de tipos. 


\subsection{Os primeiros livros}

No início de 2008, após realizar alguns trabalhos com Ademir Matias, o fascínio pela impressão tipográfica e o apreço pelos livros fez com que Flávio Vignoli criasse a Tipografia do Zé, uma editora de livros artesanais com tiragem limitada, em que o aspecto tátil da impressão tipográfica, o cuidado com a seleção dos materiais e a qualidade gráfica são as características principais.

Inicialmente, criou a coleção "Escrituras TIPOgráficas", que tinha como objetivo publicar textos de referência de autores consagrados da poesia de língua portuguesa. O primeiro título dessa coleção foi Tabacaria (Figura 1), escrito em 1928 por Fernando Pessoa (18881935), sob o heterônimo de Álvaro de Campos, e, embora o texto estivesse completando 80 anos, Vignoli explica em seu depoimento que a escolha se deveu em parte à estima que ele tem em relação ao poema e à representatividade do texto na obra de Pessoa. Todavia, podemos observar em Tabacaria um eu-lírico hesitante que, entre negações e afirmações, se vê dividido entre sonho e realidade, o que nos leva a supor que a escolha seria uma expressão subjetiva dos anseios de Vignoli para sua recém-criada editora em contraponto às tarefas diárias. O projeto gráfico do livro é de autoria de Flávio, com composição e impressão de Ademir Matias e encadernação de Laura Bastos - esta última designer, diretora de teatro e esposa de Vignoli.

Figura 1 Tabacaria e Navio Negreiro, 2008.

Fonte: Elaborado pelo autor, com base na pesquisa realizada.
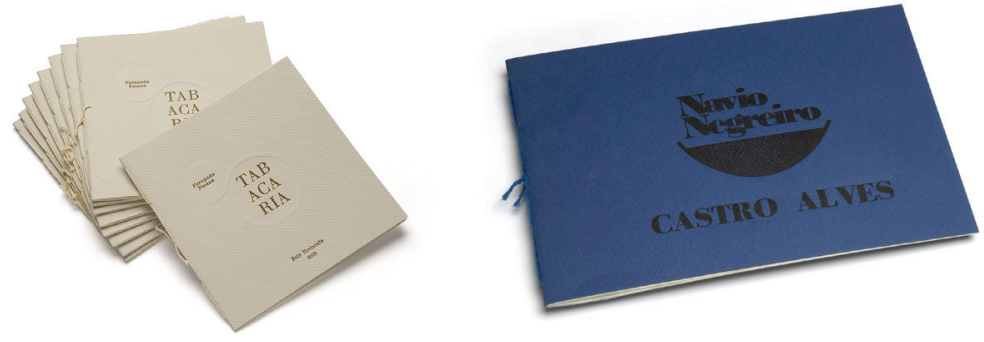

O segundo livro publicado pela Tipografia do Zé foi Navio Negreiro (Figura 1), de Castro Alves (1847-1871), lançado em maio do mesmo ano em comemoração aos 120 anos da Abolição da Escravatura. Nesse projeto, Vignoli combinou tipos de metal - para a composição do texto do miolo - com clichês de zinco - estes utilizados para a capa e demais ilustrações tipográficas no miolo. Grandes áreas de impressão chapadas foram feitas utilizando uma blanqueta ofsete como matriz de impressão. A composição manual do texto ficou sob responsabilidade de Alverando Garcia (tipógrafo apresentado a Flávio por Rafael 
Neder), a impressão ficou a cargo de Ademir Matias e encadernação foi realizada pela empresa Frente e Verso.

Figura 2 Três páginas d'Os Sertões de Euclides da Cunha no Sertão Encarnado, 2008. Fonte: Elaborado pelo autor, com base na pesquisa realizada.
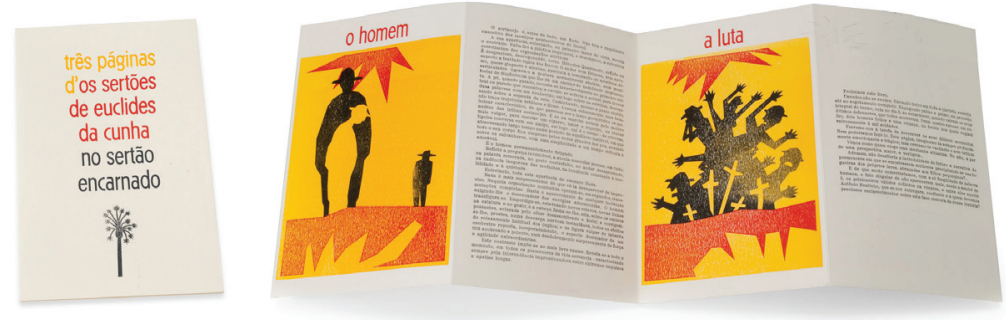

Além dos livros da coleção "Escrituras TIPOgráficas”, naquele momento Flávio tinha intenção de criar um segmento de projetos especiais para a Tipografia do Zé. A primeira encomenda dessa natureza foi um folheto produzido especialmente, em agosto de 2008, para o encerramento da exposição Sertão Encarnado, que o designer organizara na Biblioteca Estadual Luís de Bessa. Com o título de Três Páginas d'os Sertões de Euclides da Cunha (1866-1909) no Sertão Encarnado (Figura 2), o folheto apresenta três fragmentos de $O s$ Sertões, de Euclides da Cunha, que versam respectivamente sobre os temas terra, homem e luta. O projeto foi impresso por Ademir Matias e o texto composto em tipos móveis por Alverando Garcia e Rafael Neder; além disso, o folheto traz quatro ilustrações de autoria do designer, ilustrador e professor Roberto Luís Marques. Além do livreto, Roberto também participou como ilustrador da exposição; em ambos os casos, as formas angulosas dos desenhos tinham como objetivo remeter à aparência das xilogravuras populares e, para alcançar esse resultado, as ilustrações foram construídas a partir do recorte manual de papel colorido que foi posteriormente digitalizado. Um aspecto curioso desse projeto é que, embora a aparência angulosa semelhante à xilogravura tenha sido planejada desde o início para a exposição e para o folheto, durante a impressão do volante, a dureza do cliché de zinco, combinada à rugosidade do papel e à pressão inadequada da máquina impressora, começou a influenciar de tal maneira a textura das ilustrações que as inconsistências foram incorporadas ao projeto, aproximando-o ainda mais do referencial estético desejado.

Um dos grandes empecilhos da utilização tipográfica no contexto contemporâneo é a velocidade da composição tipográfica. A necessidade de conciliar seus afazeres profissionais com a Tipografia do Zé fazia com que Flávio buscasse auxílio para a composição dos textos seja com Ademir, Alverando ou Rafael. Porém, nos meses seguintes ao lançamento do folheto Três páginas d'Os Sertões de 
Euclides da Cunha no Sertão Encarnado, diante da necessidade de atender com rapidez a uma nova encomenda de projeto especial, Flávio precisou buscar um novo parceiro para a composição tipográfica de seus trabalhos. Seguindo as indicações de Ademir Matias, Vignoli conseguiu encontrar o linotipista Ilton Fernandes, na época proprietário da última linotipadora em atividade comercial na cidade de Belo Horizonte. Ilton nasceu em 1943 e aos 17 anos iniciou seu aprendizado como linotipista, passando por diferentes empresas - dentre elas o jornal Estado de Minas - até que, em 1977, fundou a Compositora Fernandes. Assim, com o auxílio de Ilton para a composição mecânica do texto, Flávio projetou o livro O elixir do pajé, de Bernardo Guimarães (1825-1884), sob encomenda da empresa Via Social (Figura 5). O projeto gráfico deste título é assinado por Vignoli e por Laura Bastos, e o formato adotado para o livro foi o de uma caixa de papel presa por elásticos que guarda em seu interior o miolo com o texto. Juntamente à costura da encadernação, havia um pequeno patuá feito de ervas aromáticas de maneira a reforçar o desejo de um feliz ano novo.

Figura 3 O elixir do pajé e Céu Inteiro, ambos de 2008.

Fonte: Elaborado pelo autor, com base na pesquisa realizada.
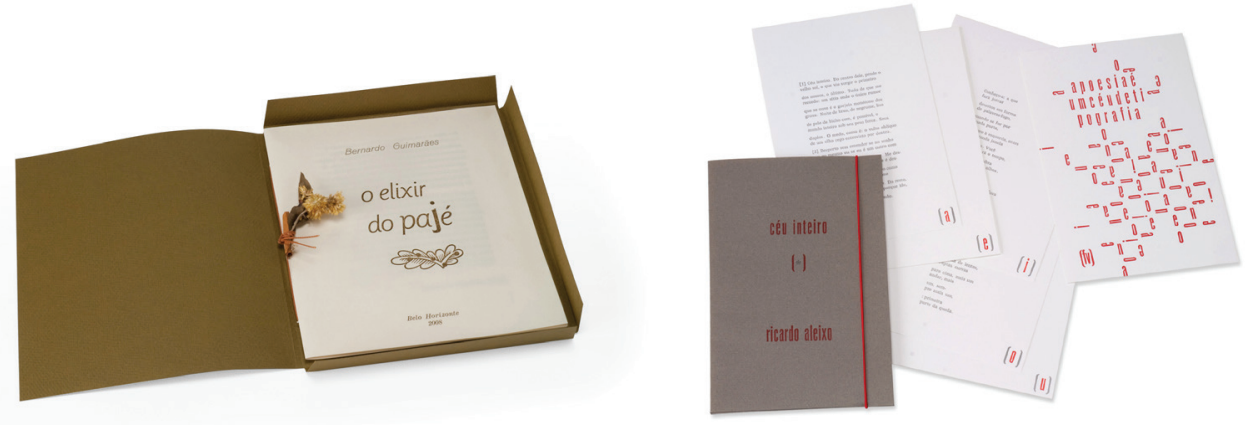

Em paralelo à produção de O elixir do pajé, também no final de 2008 Vignoli publica o livro Céu Inteiro (Figura 3), do poeta, escritor e artista Ricardo Aleixo. O título foi o primeiro livro do que viria a ser a "Coleção Elixir", voltada para autores contemporâneos e coeditada por Vignoli e Aleixo. Embora o nome da coleção tenha sido influenciado pelo título da poesia de Bernardo Guimarães, é digno de nota recorrer ao significado da palavra "elixir", que nos remete a uma bebida deliciosa, balsâmica ou confortadora. O livro de Aleixo se caracteriza como um conjunto de cinco lipogramas, que são textos literários onde se omite intencionalmente uma determinada letra, escritos em 2007, e que são acompanhados de uma gravura tipográfica de autoria de Flávio. Nesse título, o designer contou com o auxílio de Ilton Fernandes para a composição mecânica de parte do texto. Uma novidade é que nesse título Vignoli também se envolveu de uma 
maneira mais direta, além de com o projeto gráfico, com a composição manual e com a impressão, conjuntamente com Rafael Neder e Ademir Matias.

No início de 2009, após transferir seu estúdio de design gráfico para um novo espaço, Flávio decide aumentar a frequência das publicações da Tipografia do Zé e, assim, amplia seu acervo de máquinas e tipos, adquirindo novos itens. Dentre os impressos publicados naquele período destacam-se os títulos: Hino à preguiça; Livro do Desassossego: improvisações gráficas; Desterro e Auto-Retrato (Figura 4).

Figura 4 Hino à preguiça, Livro do Desassossego: improvisações gráficas, Desterro e Autorretrato, 2009. Fonte: Elaborado pelo autor, com base na pesquisa realizada.
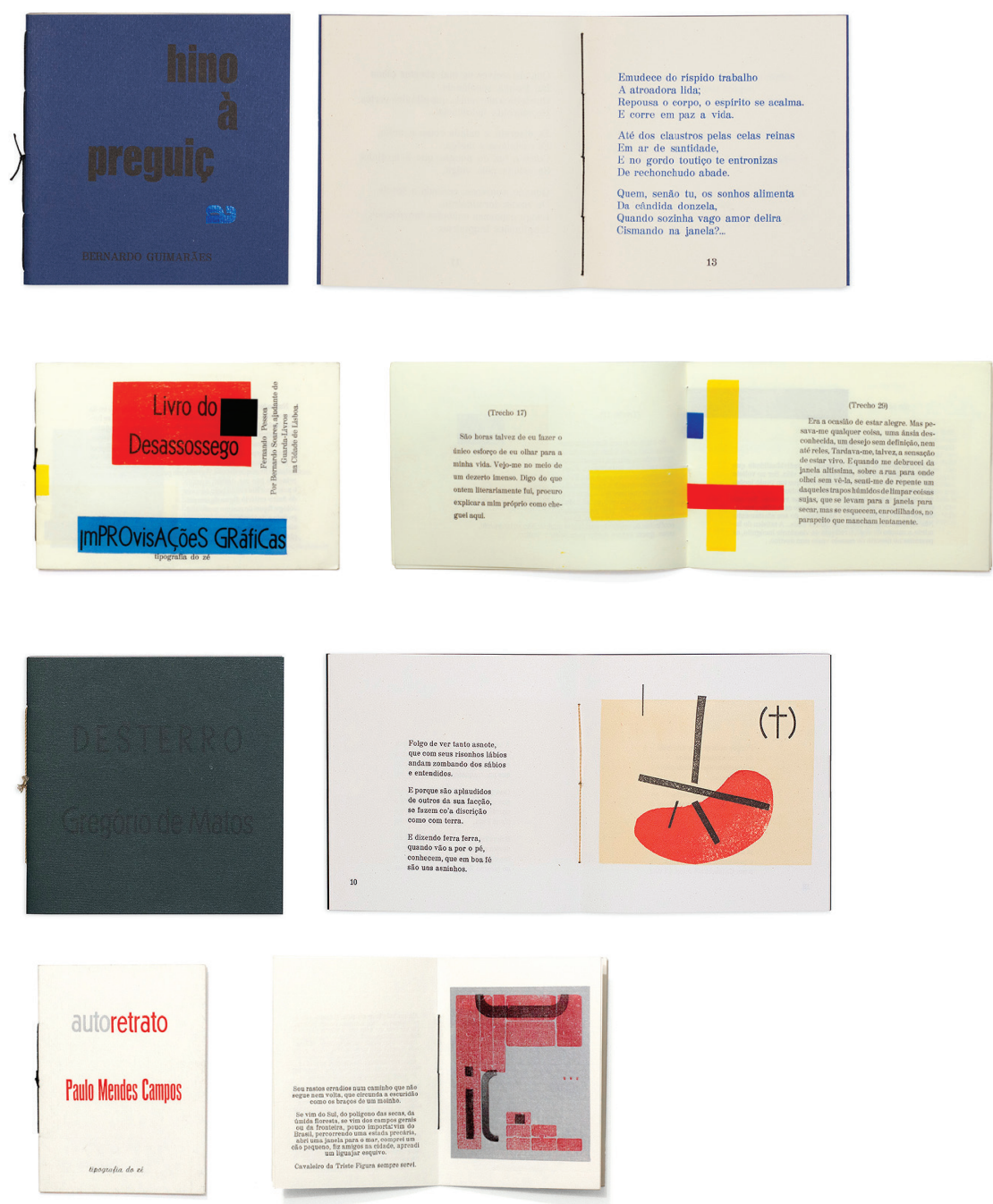

Hino à preguiça, de Bernardo Guimarães, foi lançado em abril daquele ano, e nele Flávio assina o projeto gráfico, enquanto a composição e a impressão ficaram a cargo de Wilson Bretas, com acabamento e hot-stamping de Ademir Matias, e encadernação do artista e encadernador Lucas Dupin. Para Livro do Desassossego: 
improvisações gráficas, Vignoli seleciona trechos do texto de Pessoa interferindo graficamente com gravuras abstratas feitas com recortes de blanquetas de impressão ofsete e com adesivos autocolantes. Em Desterro, de Gregório de Matos (1663-1696), e Auto-Retrato, de Paulo Mendes Campos (1921-1991), Flávio combina o texto tipográfico com a gravura. Para o primeiro, cria uma ilustração, combinando blanqueta e tipos móveis, que evoca a religião, a violência e o sentimento do poeta em relação a seu banimento do Brasil colônia. Já para o segundo, combina tipos, lingotes, quadrados e blanqueta de maneira abstrata.

No ano seguinte, publica novos textos para a "Coleção Elixir", dentre eles Melodramas: sete poemas (1977-2010) (Figura 5), do poeta, artista visual e tipógrafo ouro-pretano Guilherme Mansur. Para auxiliá-lo no projeto e produção dessa edição convidou Rafael Neder, com quem divide a autoria do projeto gráfico, a composição e a impressão. O livro funcionou como um laboratório para os designers e aprendizes de impressores, uma vez que cada poema foi interpretado graficamente, explorando o aspecto verbo-visual do texto de Mansur, que também colaborou com sugestões de leiaute para alguns poemas (Neder, Vignoli, 2012).

Figura 5 Melodramas: sete poemas, 2010

Fonte: Elaborado pelo autor, com base na pesquisa realizada.
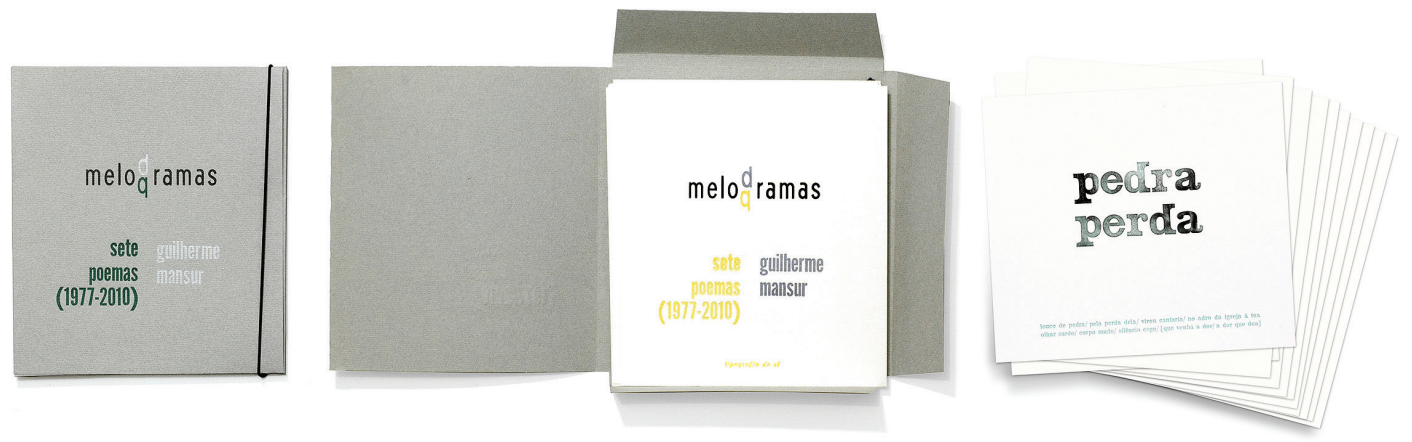

Nos meses seguintes, projeta e produz o livro Mundo torto (Figura 6), da escritora alagoana Gláucia Machado, que foi lançado em Maceió em dezembro de 2010. No livro, Vignoli combina o formato de pasta com o do caderno costurado à mão. Na pasta, uma aba se transforma em uma orelha que traz a apresentação de Ricardo Aleixo para a edição; no caderno, a transparência das folhas de papel vegetal colabora para a construção de uma atmosfera leve, porém confusa, desse mundo vivido pela poeta. Além do projeto gráfico, Flávio também assina a impressão e a composição manual; a composição mecânica ficou sob responsabilidade de Ilton Fernandes, e o acabamento a cargo de Ademir Matias. 
Figura 6 Mundo torto, 2010

Fonte: Elaborado pelo autor, com base na pesquisa realizada.

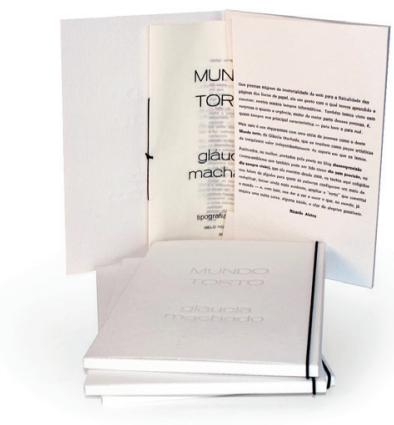

Em 2009, Vignoli conhece o artista visual pernambucano Paulo Bruscky e desse encontro surge a vontade de realizarem um trabalho conjunto, projeto que só foi retomado em 2011, quando Bruscky optou por publicar um conjunto de dez poemas inéditos, escritos em diferentes momentos de sua vida, compreendendo o período cronológico que vai de 1967 à 2008 (Figura 7). Tanto o projeto gráfico quanto a composição tipográfica são assinados em conjunto pelos designers Vignoli e Rafael Neder, enquanto a impressão e o acabamento ficaram por conta de Ademir Matias, com o auxílio de Pedro Ivo - este último monitor nos cursos da Tipografia Matias.

Figura 7 Arquivo Impresso, de Paulo Bruscky

Fonte: Elaborado pelo autor, com base na pesquisa realizada.

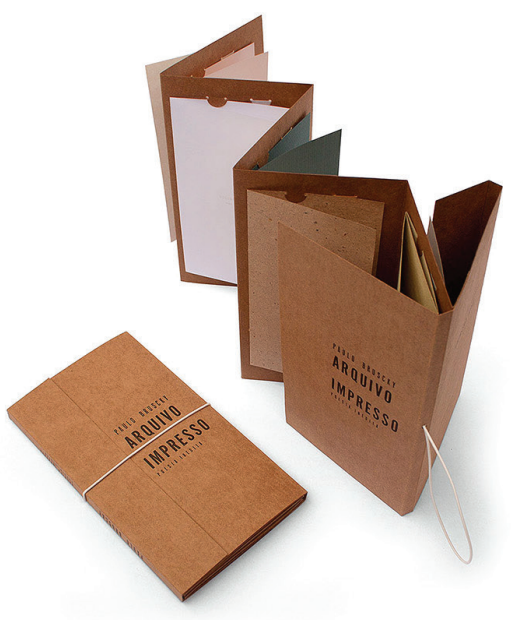

No segundo semestre daquele ano editam, para a coleção "Elixir", o livro Pá, Pum., de autoria do poeta cearense Eduardo Jorge e da catarinense Lucila Vilela (Figura 8). No projeto gráfico, Flávio explora os tipos de madeira e metal e sua relação com o som e o espaço da página: ao longo das 28 páginas que compõem o caderno do miolo, a posição da mancha de texto e da expressão "pá, pum” oscilam, 
evocando uma eventual sonoridade. O livro tem projeto gráfico de Flávio Vignoli, com composição mecânica de Ilton Fernandes, e foi impresso em dezembro de 2011 por Ademir Matias; o lançamento, porém, só aconteceu em janeiro de 2012.

Figura 8 Pá, pum., de Eduardo Jorge e Lucila Vilela

Fonte: Elaborado pelo autor, com base na pesquisa realizada.
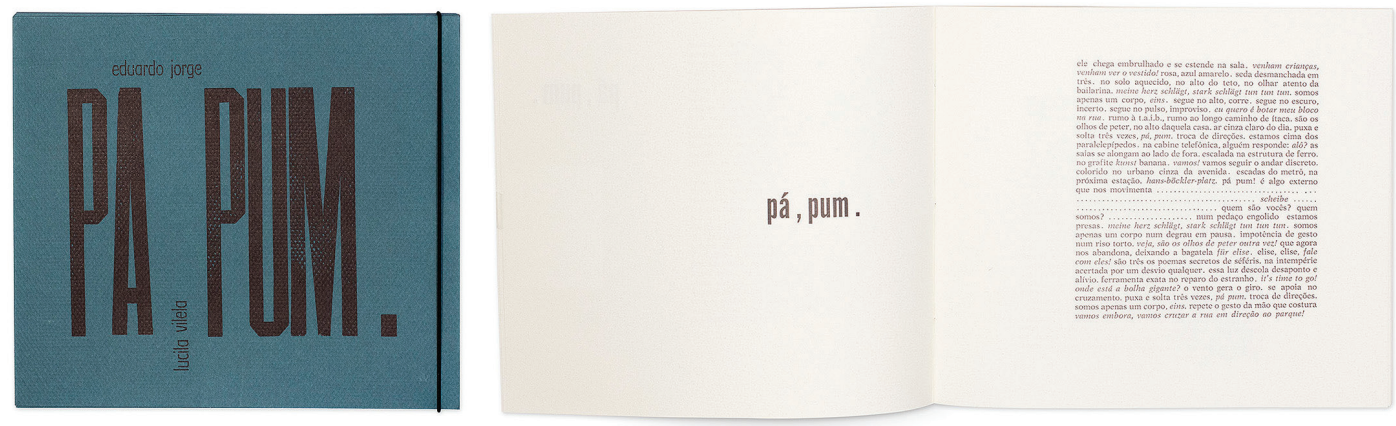

Em 2012, conjuntamente com Oséias Ferraz, da editora Crisálida, publica As janelas, do poeta alemão Rainer Maria Rilke (1875-1926), com trechos da edição homônima publicada em 2009 pela editora Crisálida (Figura 9). Enquanto o texto principal foi composto em linotipo por Ilton Fernandes e impresso por Ademir Matias, Flávio ficou responsável pela concepção do projeto gráfico do livro e pela impressão das 10 gravuras que ele chama de "janelas tipográficas", as quais acompanham cada um dos poemas. Nessas gravuras, combina tipos de madeira, blanqueta e lingões de chumbo, sobrepondo-os com diferentes cores e criando cada uma das ilustrações.

Figura 9 As janelas, 2012

Fonte: Elaborado pelo autor, com base na pesquisa realizada.
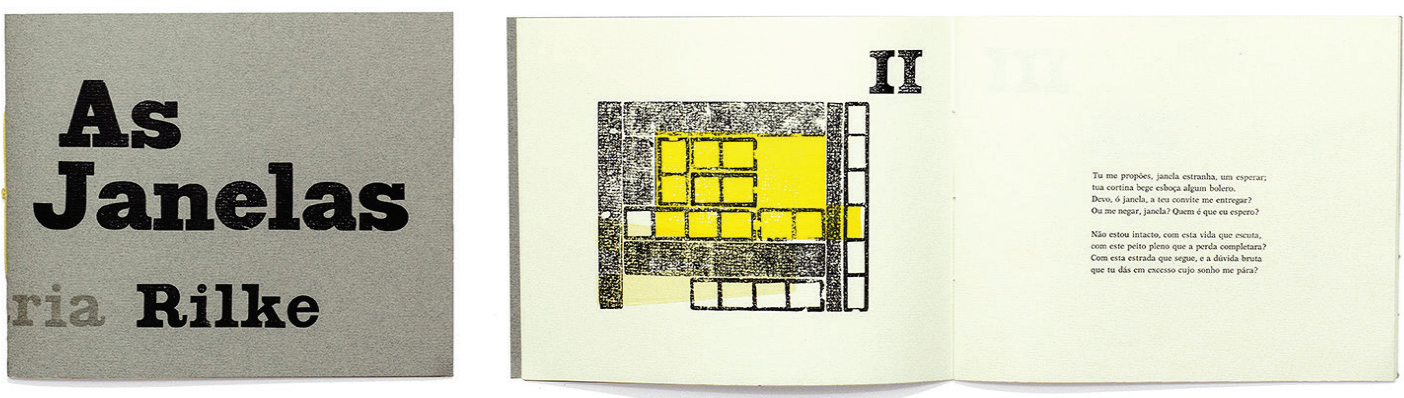


\subsection{O Museu Vivo Memória Gráfica e o Pão de Santo Antônio}

No segundo semestre de 2012, devido ao fechamento da Compositora Fernandes, adquire de Ilton Fernandes a compositora Intertype e suas respectivas gavetas de matrizes. Devido às dimensões da máquina, opta por cedê-la em comodato para o Museu Vivo Memória Gráfica, do qual era um dos conselheiros e coordenadores. O museu é ligado à UFMG e foi inaugurado em agosto de 2011 em Belo Horizonte, tendo seu acervo montado principalmente a partir de empréstimos e doações como as da ONG Memória Gráfica Typographia Escola de Gravura e reminiscências do acervo da Escola de Arquitetura da UFMG. O museu, que conta com um pequeno parque gráfico com impressoras, prelos, cavaletes de tipos, e outros equipamentos funciona como um ateliê aberto que atua além da proteção do acervo, oferecendo cursos relacionados à cultura e fabricação do livro. Com a necessidade de se dedicar mais à consolidação desse novo espaço, além de se dedicar a outros projetos profissinais, em 2013 Vignoli diminui as atividades da Tipografia do Zé e começa a atuar no museu como coordenador gráfico onde em conjunto com as professoras Ana Utsch e Maria Dulce Peixoto Barbosa começa a trabalhar na produção de novos projetos editoriais para o espaço.

Desse envolvimento com o Museu Vivo Memória Gráfica, surgiu a oportunidade de colaborar com a criação do Museu Tipografia Pão de Santo Antônio na cidade de Diamantina/MG. O museu é derivado do acervo tipográfico das gráficas dos jornais diamantinenses Pão de Santo Antônio e Voz de Diamantina, que circularam entre os anos de entre 1906 e 1990. Além de auxiliar na conecepção do espaço trabalha em conjunto com as professoras Ana Utsch e Maria Dulce Peixoto Barbosa começa a trabalhar na produção de novos projetos editoriais para o museu.

\subsection{O retorno à Tipografia do Zé}

Uma vez terminado esses projetos, Vignoli volta a produzir suas edições na Tipografia do Zé. Entre 2014 e 2015, com o interesse de divulgar sua produção para um público mais amplo, lança uma série de cadernos de notas impressos tipograficamente. Entre o segundo semestre de 2014 e o primeiro semestre de 2015 lança a série Tempo (Figura 10) e o Caderno do Traço(a) (Figura 11). 


\section{Figura 10 Caderno do Traço, 2015}

Fonte: Elaborado pelo autor, com base na pesquisa realizada.
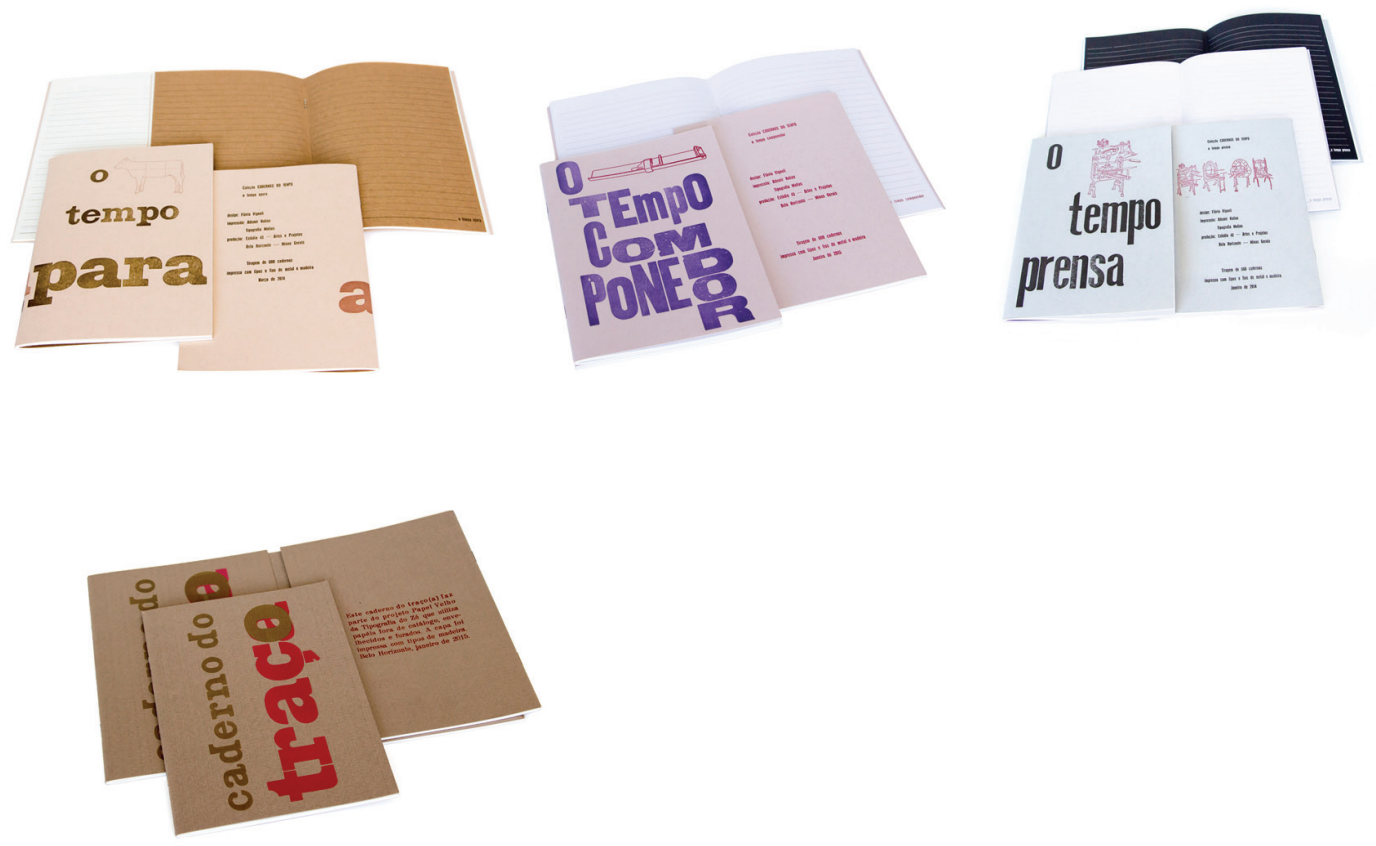

Já no segundo semestre de 2015, após organizar uma exposição do designer e artista gráfico Roberto Marques produz o livro Pareidolia Tipográfica com o qual inicia a coleção Gráfica Utópica, dedicada a livros gráficos e experimentais (Figura 12).

Figura 11 Pareidolia, 2015

Fonte: Elaborado pelo autor, com base na pesquisa realizada.

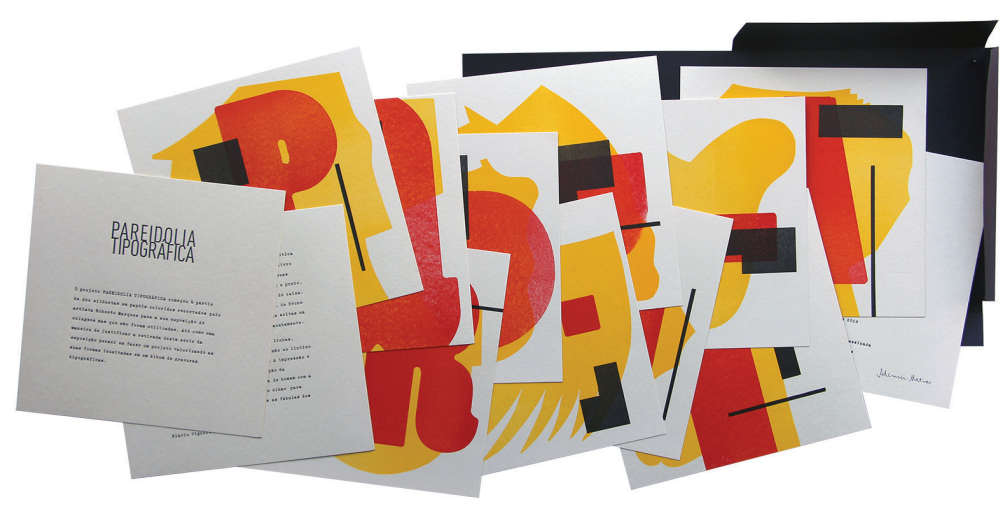




\title{
3 Considerações Finais
}

Este artigo, buscou apresentar resumidamente a produção gráfica de Flávio Vignoli e sua Tipografia Zé. Tal registro se faz necessário frente a qualidade gráfica do material produzido além da particularidade do resgate da impressão tipográfica. A produção de Vignoli evidencia como a manifestação tardia da impressão tipográfica se utiliza de uma estratégia pluralista, condizente com os questionamentos e anseios do design gráfico contemporâneo. Constatou-se a riqueza visual e verbal de muitos dos projetos analisados. Assim, pensar o design contemporâneo envolve compreender a sua complexidade, onde antigos paradigmas são confrontados e o designer mais do que um solucionador, transforma-se em um formulador de problemas tornando-se autor, editor e financiador de seus próprios projetos.

\section{REFERÊNCIAS}

DELGADO, Lucília de Almeida Neves. História Oral: memória, tempo, identidades. Belo Horizonte: Autêntica, 2010.

DRUCKER, Johanna. The Visible Word: Experimental Typography and Modern Art, 1909-1923. Chicago: University of Chicago Press, 1996.

JURY, David. Lettepress: New applications for traditional skills. Rotovision, 2006.

NEDER, R.; VIGNOLLI, Flávio. Reinventando os Tipos: a impressão tipográfica como possibilidade de experimentação gráfica. In: $2^{\mathrm{a}}$ Conferência Internacional em Design e Artes Gráficas, 2013, Tomar. Livro de Actas. Lisboa: ISEC/IPT, 2012. p. 252-254.

ROCHA, Claudio. Materialidade Digital. In: CAMPOS, Gisela Belluzzo de; LEDESMA, María. Novas Fronteiras do Design Gráfico. São Paulo: Estação das Letras e Cores, 2011. p. 151-157.

VIGNOLI, Flavio. Flávio Vignoli: Depoimento [28 Jun. 2013]. Entrevistador: Rafael Neder. Belo Horizonte, 2013. DVD (1h 05min).

\section{Sobre os autores}

\author{
Rafael Neder (Mestre) \\ <rafael@rafaelneder.com.br> \\ Universidade FUMEC (MG) \\ Departamento de Design \\ Centro Universitário SENAC-SP (SP) \\ Unidade Lapa Scipião
}


Neder R., \& Campos G. B. | Dos livros aos tipos: um inventário gráfico da tipografia do Zé

Gisela Belluzzo de Campos (Doutora)

giselabelluzzo@uol.com.br

Universidade Anhembi Morumbi

Programa de Pós-graduação Stricto Sensu em Design

Edição especial P\&D2016

Artigo recebido em 23/09/2016

Artigo aceito em 30/09/2016 